\title{
Optimal Feeder Reconfiguration of Distribution System with Distributed Generation Units using HC-ACO
}

\author{
Manas Ranjan Nayak \\ Deptt. of Electrical Engg. , I.T.E.R., Siksha ‘o’ Anusandhan University, Bhubaneswar, 751030, \\ Odisha, India, \\ manasnk72@gmail.com

\begin{abstract}
The objective of optimal feeder reconfiguration of radial distribution system problem is to obtain the best set of branches to be opened, one each from each loop, such that the resulting radial distribution system has the desired performance. This paper presents a feeder reconfiguration problem in the presence of distributed generators to minimize the system power loss while satisfying operating constraints using Hyper Cube-Ant Colony Optimization (HC-ACO) algorithm. Loss Sensitivity analysis is used to identify optimal location for installation of DG units. Simulations are conducted on 33 - bus radial distribution system at four different cases to verify the efficacy of the proposed method with other recent published approaches reported in the literature. The result shows that the method proposed is fast and effective.
\end{abstract}

Keyword: Distribution system, radial distribution system, Distribution feeder reconfiguration, Distributed generator, Ant Colony Optimization (ACO) algorithm, Real power loss.

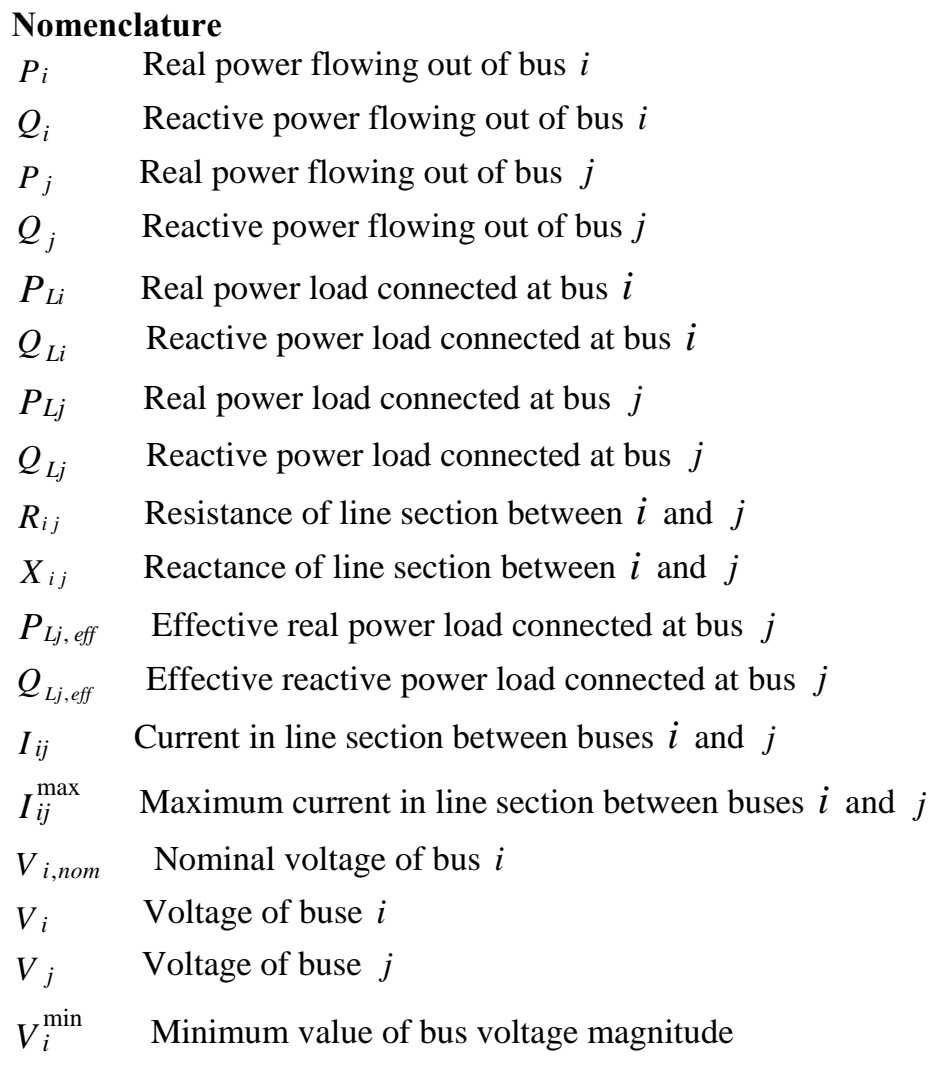

Received: December $12^{\text {nd }}, 2013$. Accepted: February $24^{\text {th }}, 2014$ 


$\begin{array}{ll}V_{i}^{\max } & \text { Maximum value of bus voltage magnitude } \\ P_{\text {Loss }}(i, j) & \text { Real power loss of the line section between buses } i \text { and } j \\ P_{T, \text { Loss }} & \text { Total real power loss } \\ n & \text { Total number of buses } \\ A & \text { Bus incidence matrix } \\ P_{S U B} & \text { Real power injection of substation } \\ Q_{S U B} & \text { Reactive power injection of substation } \\ P_{D G i} & \text { Real power generation of the DG connected at bus } i \\ Q_{D G i} & \text { Reactive power generation of the DG connected at bus } i \\ P_{D G, i}^{\min } & \text { Lower limit of active power generation of the DG connected at bus } i \\ P_{D G, i}^{\max } & \text { Upper limit of active power generation of the DG connected at bus } i \\ Q_{D G, i}^{\min } & \text { Lower limit of reactive power generation of the DG connected at bus } i \\ Q_{D G, i}^{\max } & \text { Upper limit of reactive power generation of the DG connected at bus } i \\ p . f_{D G i} & \text { Power factor of the DG connected at bus } i\end{array}$

\section{Introduction}

Electrical power distribution system consists of groups of interconnected radial circuits. They have switches to configure the networks via switching operations to transfer loads among the feeders. There are two types of switches used in the distribution system, sectionalizing switches (normally closed switches) and tie switches (normally open switches), whose states determine the configuration of network. The configuration of the distribution system is changed by opening sectionalizing switches and closing tie switches so that the radial structure of the network is maintained and all of the loads are supported and reduced power losses, improve voltage profile, improve power quality, increase system security, relieve overload in the network [1]. However, due to dynamic nature of loads, total system load is more than its generation capacity that makes relieving of load on the feeders not possible and hence voltage profile of the system will not be improved to the required level. In order to meet required level of load demand, DG units are integrated in distribution network to improve voltage profile, to provide reliable and uninterrupted power supply and also to achieve economic benefits such as minimum power loss, energy efficiency and load leveling. Network reconfiguration and DG placement in distribution networks are considered independently. But, in the proposed method, network reconfiguration and then DG installation are done for improved loss minimization and voltage profile.

Since network reconfiguration is a complex combinatorial, non-differentiable constrained optimization problem, many algorithms are proposed in the past. Merlin and Back [2], first proposed network reconfiguration problem and they used a branch-and- bound-type optimization technique. The drawback with this technique is the solution proved to be very time consuming as the possible system configurations are, where line sections equipped with switches is. Based on the method of Merlin and Back [2], a heuristic algorithm has been suggested by Shirmohammadi and Hong [3]. The drawback with this algorithm is simultaneous switching of the feeder reconfiguration is not considered. A heuristic algorithm [4] was suggested, where a simple formula was developed to determine change in power loss due to a branch exchange. The disadvantage of this method is only one pair of switching operations is considered at a time and reconfiguration of network depends on the initial switch status. An algorithm [5] was presented based on the heuristic rules and fuzzy multi-objective approach for optimizing network configuration. The disadvantage in this is criteria for selecting membership 
functions for objectives are not provided. A solution using a genetic algorithm (GA) [6] was presented to look for the minimum loss configuration in distribution system. A refined genetic algorithm (RGA) [7] was presented to reduce losses in the distribution system. In RGA, the conventional crossover and mutation schemes are refined by a competition mechanism. Harmony Search Algorithm (HSA) [8] was proposed to solve the network reconfiguration problem to get optimal switching combinations simultaneously in the network to minimize real power losses in the distribution network.

Many methods are proposed for the best placement and sizes of DG units which is also a complex combinatorial optimization problem. An analytical method [9] was introduced to determine optimal location to place a DG in distribution system for power loss minimization. A Lagrangian based approach to determine optimal locations for placing DG in distribution systems considering economic limits and stability limits was presented by Rosehart and Nowicki [10]. A multi-objective algorithm using GA [11] was presented for sitting and sizing of DG in distribution system. Placement and penetration level of the DGs under the SMD framework was discussed by Agalgaonkar [12].

This paper is to propose a 33- bus radial feeder reconfiguration technology based on the Hyper-Cube (HC) Framework Ant Colony Optimization (ACO) algorithm with DG to minimize system real power loss and bus voltage deviation in the distribution network without violating operation constraints and maintaining the radial structure. The HC-ACO algorithm is a useful evolutionary algorithm with strong global search ability. The characteristics of the HCACO algorithm include positive feedback, distributed computation and a constructive greedy heuristics. Positive feedback makes sure of a rapid search for a global solution; distributed computation avoids premature convergence, and constructive greedy heuristics help find acceptable solution as soon as possible. These properties are counterbalanced by the fact that, for some applications, the HC-ACO can outperform other heuristics.

The rest of the paper is organized as follows: In section II, modelling of power flow in radial distribution network is discussed. Modelling of DG units are given in section III. Sensitivity analysis for DG installation is given in section IV. In section V, the problem formulation is described. The Ant Colony Optimization is briefed in section VI. In section VII, application of Ant Colony Optimization in the Hyper-Cube (HC) Framework to solve problem is described. The test system, numerical results and discussion are presented in section VIII and Section IX, concludes this paper.

\section{Modeling of power flow using backward and forward sweep method}

In this paper, network topology based backward and forward sweep method [13] is used to find out the load flow solution for balanced radial distribution system. Conventional NR and Gauss Seidel (GS) methods may become inefficient in the analysis of distribution systems, due to the special features of distribution networks, i.e. radial structure, high $\mathrm{R} / \mathrm{X}$ ratio and unbalanced loads, etc. These features make the distribution systems power flow computation different and somewhat difficult to analyze as compared to the transmission systems. Various methods are available to carry out the analysis of balanced and unbalanced radial distribution systems and can be divided into two categories. The first type of methods is utilized by proper modification of existing methods such as NR and GS methods. On the other hand, the second group of methods is based on backward and forward sweep processes using Kirchhoff's laws. Due to its low memory requirements, computational efficiency and robust convergence characteristic, backward and forward sweep based algorithms have gained the most popularity for distribution systems load flow analysis. The voltage magnitude and phase angle of the source should to be specified. Also the complex values of load demands at each node along the feeder should be given. Starting from the end of the feeder, the backward sweep calculates the line section currents and node voltages (by KCL and KVL) back to the source. The calculated voltage at the source is compared with its original specified value. If the error is beyond the limit the forward sweep is performed to update the node voltages along the feeder. In such a case, the specified source voltage and the line section currents already calculated in the 
previous backward sweep are used. The process keeps going back and forth until the voltage error at the source becomes within the limit. The shunt admittance at any bus to ground is not considered. It is assumed that the three-phase radial distribution network is balanced and can be represented by their equivalent single-line diagram. Figure 1 represents the electrical equivalent of a typical branch of a distribution system.



Figure 1. Distribution system with DG installation at any location.

\section{A. Backward Sweep}

By starting from the ending buses and moving backward to the slack bus (substation bus), the power flow through each branch is expressed by the following set of recursive equations:

$$
\begin{aligned}
& P_{i}=P_{j}+P_{L j}+R_{i j} \cdot \frac{P_{j}^{\prime 2}+Q_{j}^{\prime 2}}{\left|V_{j}\right|^{2}} \\
& Q_{i}=Q_{j}+Q_{L j}+X_{i j} \cdot \frac{P_{j}^{\prime 2}+Q_{j}^{\prime 2}}{\left|V_{j}\right|^{2}} \\
& \left|V_{i}\right|^{2}=\left|V_{j}\right|^{2}-2\left(R_{i j} \cdot P_{j}^{\prime}+X_{i j} \cdot Q_{j}^{\prime}\right)+\left(R_{i j}^{2}+X_{i j}^{2}\right) \cdot \frac{P_{j}^{\prime 2}+Q_{j}^{2}}{\left|V_{j}\right|^{2}}
\end{aligned}
$$

Where $P_{j}^{\prime}=P_{j}+P_{L j}$ and $Q_{j}^{\prime}=Q_{j}+Q_{L j}$

\section{B. Forward Sweep:}

By starting from the slack bus (substation bus) and moving forward to ending bus, the active and reactive power flows at the receiving end of branch $\left(P_{j}\right.$ and $Q_{j}$ ) and the voltage magnitude at the receiving end $\left(\left|V_{j}\right|\right)$ are expressed by the following set of recursive equations:

$$
\begin{aligned}
& P_{j}=P_{i}-P_{L j}-R_{i j} \cdot \frac{P_{i}^{2}+Q_{i}^{2}}{\left|V_{i}\right|^{2}} \\
& Q_{j}=Q_{i}-Q_{L j}-X_{i j} \cdot \frac{P_{i}^{2}+Q_{i}^{2}}{\left|V_{i}\right|^{2}} \\
& \left|V_{j}\right|^{2}=\left|V_{i}\right|^{2}-2\left(R_{i j} \cdot P_{i}+X_{i j} \cdot Q_{i}\right)+\left(R_{i j}^{2}+X_{i j}^{2}\right) \cdot \frac{P_{j}^{2}+Q_{j}^{2}}{\left|V_{j}\right|^{2}}
\end{aligned}
$$


Hence, if the $V_{o}, P_{o}, Q_{o}$ at the first bus of the network are known, then the same quantities at the other nodes can be calculated by applying the above branch equations.

By applying the backward and forward update methods, we can get a power flow solution. The real power loss of the line section connecting between buses $i$ and $j$ is calculated as

$$
P_{\text {Loss }}(i, j)=R_{i j} \cdot \frac{P_{i}^{2}+Q_{i}^{2}}{\left|V_{i}\right|^{2}}
$$

The total real power loss of the all lines sections in $n$ bus system ( $P_{T, \text { Loss }}$ ) is calculated by adding up the losses of all line sections of the feeder, which is described as

$$
P_{T, \text { Loss }}=\sum_{i=1}^{n-1} P_{\text {loss }}(i, j)
$$

\section{Mathematical model of Distributed Generation Units}

A distributed generation (DG) unit can be modeled as either a voltage-controlled bus (PV bus) or as a complex power injection (PQ bus) in the distribution system. If DGs have control over the voltage by regulating the excitation voltage (synchronous generator DGs) or if the control circuit of the converter is used to control P and V independently, then the DG unit may be modeled as a PV type. Other DGs, like induction generator - based units or converters used to control $\mathrm{P}$ and $\mathrm{Q}$ independently, are modeled as PQ types. The most commonly used DG model is the PQ model. In this work, the PQ-DG units are represented as a negative PQ load model delivering active and reactive power to a distribution system. This gives flexibility in modeling various types of DG. DG can be classified into four major types[14] based on their terminal characteristics in terms of active and reactive power delivering / consuming capability as follows:

- Type 1: DG capable of injecting real power ( $\boldsymbol{P}_{\boldsymbol{D G} \boldsymbol{i}}$ ) only (Photovoltaic, $\boldsymbol{p} \cdot \boldsymbol{f}_{\boldsymbol{D G}}=1$ )

- Type 2: DG capable of injecting both real power $\left(P_{D G_{i}}\right)$ and reactive power $\left(\boldsymbol{Q}_{\boldsymbol{D G} \boldsymbol{i}}\right)$

(Micro Turbine, $0<p \cdot f_{D G}<1$ )

- Type 3: DG capable of injecting real power $\left(P_{D G_{i}}\right)$ but consuming reactive power $\left(Q_{D G_{i}}\right)$

(Wind Turbine, $0<p \cdot f_{D G}<1$ )

- Type 4: DG capable of injecting reactive power $\left(Q_{D G_{i}}\right)$ only

(Synchronous condenser, $p \cdot f_{D G}=0$ )

The present studies were considered with Type 1 DGs only. By considering the properties of these resources and in order to modeling them in the mentioned optimization problem, the injected active powers at bus $i$ are modeled as follows:

Type 1:

$P_{i}=P_{D G_{i}}-P_{L_{i}}$ and $Q_{i}=-Q_{L_{i}}$

\section{Sensitivity analysis for DG installation}

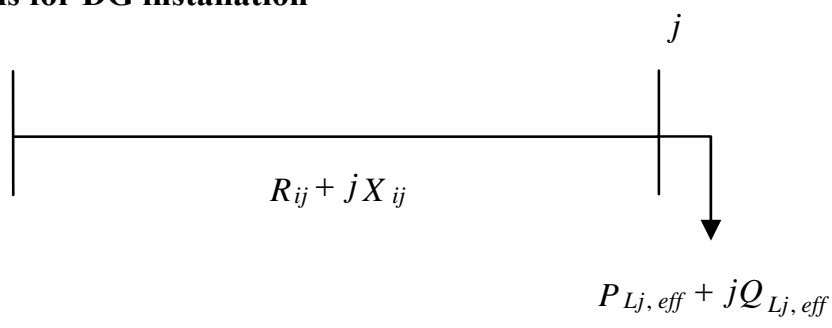


Consider a line section consisting an impedance of $R_{i j}+j X_{i j}$ and a load of connected $P_{L j, e f f}+j Q_{L j, \text { eff }}$ between $i$ and $j$ buses as given above.

The real power loss of the line section connecting between buses $i$ and $j$ is given by

$$
P_{\text {loss }}=\frac{\left(P_{L j, e f f}^{2}+Q_{L j, e f f}^{2}\right) R_{i j}}{V_{j}^{2}}
$$

The loss sensitivity factor (LSF) can be defined with the equation

$$
\frac{\partial P_{\text {loss }}}{\partial P_{L j, \text { eff }}}=\frac{2 * P_{L j, \text { eff }} * R_{i j}}{V_{j}^{2}}
$$

Using (11), LSFs are calculated from load flows and values are arranged in descending order for all buses of the given system. The LSFs decide the sequence in which buses are to be considered for DG unit installation. The size of DG unit at candidate bus is calculated using HC-ACO.

\section{Problem Formulation}

The objective function is a constrained optimization problem to find an optimal arrangement of feeder for the distribution system and DG placement in which the value of function $f(x)$ is minimized.

\section{A. Objective Function}

The objective function $f(x)$ consists of 2 goals: reducing the real power losses and improving the voltage profile in a given radial distribution system while satisfying all constraints for a fixed number of DGs and specific total capacity of the DGs.

\section{A.1. Minimization of the real power losses $\left(f_{1}\right)$ :}

The real power loss of the line section connecting buses $i$ and $j$ can be computed as

$$
P_{\text {Loss }}(i, j)=R_{i j} \frac{P_{i}^{2}+Q_{i}^{2}}{\left|V_{i}^{2}\right|}
$$

The total real power losses of the all lines sections is described as

$$
f_{1}=P_{T, \text { Loss }}=\sum_{i=1}^{n-1} P_{\text {Loss }}(i, j)
$$

\section{A.2. Minimization of Voltage deviation or Improvement the voltage profile $\left(f_{2}\right)$ :}

The objective function for minimization of voltage deviation is defined as

$$
f_{2}=V D=\sum_{i=1}^{n}\left|V_{i}-V_{i, n o m}\right|
$$




\section{B. System Constraints}

The objective function is subjected to the following constraints:

\section{B.1. Power balance constraints}

$$
\begin{aligned}
& P_{S U B}+\sum_{i=1}^{n} P_{D G, i}=\sum_{i=1}^{n} P_{L i}+P_{T, \text { Loss }} \\
& Q_{S U B}=\sum_{i=1}^{n} Q_{L i}+Q_{T, \text { Loss }}
\end{aligned}
$$

\section{B.2. Bus Voltage limit}

$$
V_{i}^{\min } \leq V_{i} \leq V_{i}^{\max }
$$

\section{B.3. Thermal Limits}

$$
I_{i j} \leq I_{i j}
$$

\section{B.4. Radial structure of the network}

$$
\operatorname{det}(\mathrm{A})=1 \text { or }-1 \text { (radial system) }
$$

$\operatorname{det}(\mathrm{A})=0$ (not radial)

B.5. Power limits of $D G$ :

$$
P_{D G, i}^{\min } \leq P_{D G, i} \leq P_{D G, i}^{\max }
$$

\section{General description of ant colony optimization algorithm}

Ant Colony Optimization (ACO) is a recently proposed metaheuristic approach for solving hard combinatorial optimization problems. The inspiring source of ACO is the pheromone trail laying and following behavior of real ants which use pheromone as a communication medium. In analogy to the biological example, ACO is based on the indirect communication of a colony of sample agents, called artificial ants, mediated by artificial pheromone trails. The pheromone trails in ACO serve as distributed, numerical information which the ants use to probabilistically construct solutions to the problem being solved and which the ants adapt during the algorithm's execution to reflect their search experience [15, 16 \&17].

Artificial ants used in ACO are stochastic solution construction procedures that probabilistically build a solution by iteratively adding solution components to partial solution by taking into account (i) heuristic information on the problem instance being solved and (ii) artificial pheromone trails which change dynamically at run time to reflect the agents' acquired search experience [15, 16 \&17].

The concept of ACO is clear but the algorithm is not unique. The model of selection of a proper algorithm depends on the application. The proposed ACO algorithm that is introduced here is shown in the flow chart of figure 2. The following steps give explanations to the flow chart of figure 2 .

1) Close all the tie and sectionalizing switches in the network to construct meshed loops. The number of meshed loops equal the number of tie switches.

2) Generate the number of artificial ants arbitrary.

3) Initialize the parameters, heuristic parameter $(\beta)$, pheromone parameter $(\alpha)$, evaporation parameter $(\rho)$ for local updating rule, evaporation factor $(\mu)$ for global updating rule, and initial pheromone values for each switch. 
4) State transition rule:

Ants select their next state (switch) according to this rule given by (22)

$$
\begin{aligned}
& S_{k}(i, j)= \begin{cases}S_{1} & \text { if } \quad q \leq q_{0} \\
S_{2} & \text { otherwise }\end{cases} \\
& S_{1}=\arg \max \left[[\tau(i, j)]^{\alpha} \cdot\left[\eta(i, j)^{\beta}\right]\right]
\end{aligned}
$$

Where $S_{k}(i, j)$ is the state (switch) that an $t_{k}$ chooses in its next move; $k$ is the ant ; $i$ and $j$ are the current and next state respectively ; $S_{1}$ and $S_{2}$ are random variables represent the state (switch) that ant $\mathrm{k}_{\mathrm{k}}$ selects according to transition state transition rule ; $\tau(i, j)$ is the pheromone deposited by ants during move; $q$ is a random number uniformly distributed in $[0,1] ; q_{0}$ is a parameter between 0 and $1\left(0 \leq q_{0} \leq 1\right)$ according to equation (25) $; \eta(i, j)$ is the heuristic information of the problem ; $\alpha$ is a parameter represents the importance of pheromone ; $\beta$ is a parameter represents the importance of heuristic.

$S_{2}$ is selected according to a pseudo random rule or a pseudo random proportional rule given by (24)

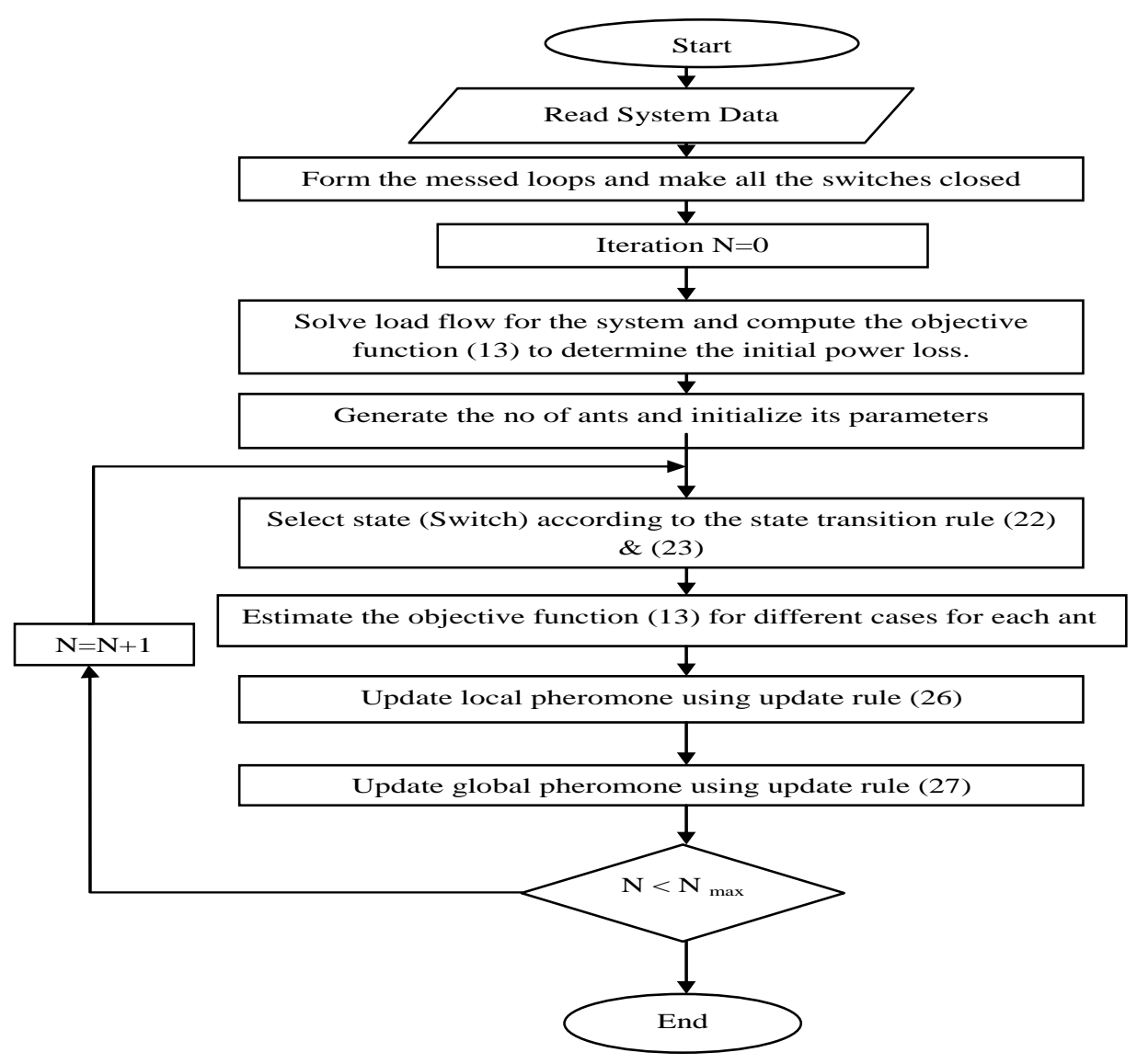

Figure 2. Flow chart of ACO algorithm 


$$
\begin{gathered}
S_{2}=\frac{[\tau(i, j)]^{\alpha} \cdot\left[\eta(i, j)^{\beta}\right.}{\sum_{l \in N_{k}(i)}[\tau(i, j)]^{\alpha} \cdot\left[\eta(i, j)^{\beta}\right.} \text { if } j \varepsilon N_{k}(i) \\
q_{0}=\left[\begin{array}{ccc}
c_{1} & \text { if } & 0 \leq \text { cycle } \leq n_{0} \\
c_{0} & \text { if } & 0 \leq \text { cycle } \leq n_{1} \\
c_{1} & \text { if } & 0 \leq \text { cycle } \leq n_{\max }
\end{array}\right.
\end{gathered}
$$

Where $N_{K}(i)$ the set of states is (switches) that selected by ant $\mathrm{k}$ that is called tabu list ; $n_{0}$ and $n_{1}$ are iteration frequency ; $n_{\max }$ is maximum iteration number; $c_{0}$ is a parameter its value between 0 and $0.4 ; C_{1}$ is a parameter its value between 0.8 and 1 .

5) Objective function calculation:

After ants finish from selecting the switches (states), the objective function is calculated for different cases of real power loss.

6) Local updating pheromone rule:

While constructing a solution each ant modifies the pheromone by this rule given by (26).

$$
\tau(i, j)=(1-\rho) \cdot \tau(i, j)+\rho \cdot \tau_{0}
$$

Where $\tau_{0}$ is the initial value of pheromone; $\rho$ is a heuristically defined parameter. The local updating rule shuffles the search process.

7) Global updating pheromone rule:

When all ants complete their tour (an iteration), this rule is applied to the states (switches) belonging to the best solution. This rule provides a great amount of pheromone to best solution and is given by (27)

$$
\begin{aligned}
& \tau(i, j)=(1-\mu) \cdot \tau(i, j)+\mu \sum_{k=1}^{m} \Delta \tau(i, j) \\
& \Delta \tau(i, j)=\left[\begin{array}{ccc}
\frac{Q}{L_{K}} & \text { if } & \text { ant } t_{k} \text { selects the edge or state }(i, j) \\
0 & \text { otherwise }
\end{array}\right.
\end{aligned}
$$

Where $\Delta \tau(i, j)$ is the change in the pheromone; $\mu$ is the pheromone evaporation factor; $Q$ is a constant between 1 and 10,000; $L_{K}$ is the best objective function solved by $a n t_{k} ; \mathrm{m}$ is the number of states.

8) Repeat step 4 to step 6 continuously until satisfying the condition of abort iteration.

9) Up to abort iteration, the solution of minimum objective function in all local optimum solution is global optimum solution.

\section{Application of ACO in the Hyper-Cube (HC) framework to solve the problem}

The (HC) framework is a recently developed framework for the general ACO [18 \& 19]. It is based on changing the pheromone update rules used in ACO algorithms so that the range of pheromone variation is limited to the interval [0-1], thus providing automatic scaling of the auxiliary fitness function used in the search process and resulting in a more robust and easier to 
implement version of the ACO procedure. The distribution system is represented as an undirected graph $G(B, L)$ composed of set $B$ of nodes and a set $L$ of arcs indicating the buses and their connecting branches (switches) respectively. Artificial ants move through adjacent buses, selecting switches that remain closed to minimize the system power losses. The solution iterates over three steps:

\section{A. Initialization:}

The Solution starts with encoding parameters by defining

(i). System parameters such as; set of supply substations $S$; set of buses $N_{B}$; set of branches $N_{R}$ where each branch has 2 possible states either " 0 " for an opened tie switch or " 1 ” for a closed sectionalizing switch); load data $P_{\text {load }}, Q_{\text {load }}$; branch data

$R_{m}, X_{m}$ base configuration of the system $C^{(0)}$ defined by the system's tie switches, initial power losses of the system $f\left(C^{(0)}\right)$ by solving the power flow for $C^{(0)}$ and evaluating the fitness function $f$.

(ii). Algorithm parameters such as; number of artificial ants in each iteration $N$; initial pheromone quantity $\tau_{0}$ assigned to each switch; evaporation factor of pheromone trails $\rho$; the parameters $\alpha$ and $\beta$ that determine the relative importance of the line ss pheromone versus its visibility; a counter $h$ for the number of iterations, a counter $x$ that is updated at the end of the iteration with no improvement in the objective function; maximum number of iterations $H_{\max }$, and maximum number of iterations $X_{\max }$ with no improvement in the objective function respectively. The base configuration is then set as an initial reference configuration and as the best configuration found so far such that $C_{\text {best }}=C_{\text {best }}^{(0)}=C^{(0)}$.

\section{B. Ants' Reconfiguration and Pheromone Updating:}

In each iteration $h$, a reference configuration is set as the best configuration of the previous iteration such that $C_{\text {best }}^{(h-1)}=C_{\text {ref }}^{(h)} . N$ Ants are initially located on $N$ randomly chosen open switches and are sent in parallel in such a way that each ant $n$ in the $h^{\text {th }}$ iteration introduces a new radial configuration $C_{n}^{(h)}$ by applying the state transition rule. Once all ants finish their tour, the configuration corresponding to each ant is evaluated by computing the objective function $f\left(C_{n}^{(h)}\right)$. The best configuration of the $h^{\text {th }}$ iteration $C_{\text {best }}^{(h)}$ is identified which is the configuration corresponds to the minimum evaluated objective function of all ants (minimum power loss). The best configuration of the $h^{\text {th }}$ iteration $C_{\text {best }}^{(h)}$ is compared to the best configuration so far $C_{\text {best }}$ such that if $f\left(C_{\text {best }}^{(h)}\right)<f\left(C_{\text {best }}\right)$, the overall best configuration is updated such $C_{\text {best }}=C_{\text {best }}^{(h)}$. Finally, the pheromone updating rules are applied such that for all switches that belong to the best configuration, the pheromone values are updated using (29). Otherwise, the pheromone is updated using (30).

$$
\begin{aligned}
& \tau^{(h)}=(1-\rho) \tau^{(h-1)}+\rho \sigma \\
& \tau^{(h)}=(1-\rho) \tau^{(h-1)}
\end{aligned}
$$


Where, $\tau^{(h)}$ is the new pheromone value after the $h^{\text {th }}$ iteration, $\tau^{(h-1)}$ is the old value of pheromone after the $\left(h^{\text {th }}-1\right)$ iteration, $\rho$ is arbitrarily chosen from the interval [0-1] and $\sigma$ is a heuristically defined parameter which was chosen to be equal $\left(f\left(C_{\text {best }}\right) / f\left(C_{\text {best }}^{(h)}\right)\right)$ since $f\left(C_{\text {best }}^{(h)}\right)$ cannot be lower that $f\left(C_{\text {best }}\right)$ the pheromone assigned to any switch cannot fall outside the range [0-1] so that the pheromone update mechanism is fully consistent with the requirements of the $(\mathrm{HC})$ framework.

\section{Termination Criteria:}

The solution process continues until maximum number of iterations is reached $h=H_{\max }$, or until no improvement of the objective function has been detected after specified number of iterations $x=X_{\max }$.

\section{Test system description, simulation results and analysis}

A. Test system description:

The test system is a hypothetical three phase balanced $12.66 \mathrm{KV}$ 33-bus radial distribution system. The data for the different loops within the 33-bus radial distribution system is given in appendix Table A.II. The load data and line data are given in appendix Table 1.



Figure 3. The base configuration of the 33- bus radial distribution system

The base configuration of the system is shown in Figure 3 can be defined by the system tie switches [8 - 21(33) , 9 - 15(34) ,12 - 22 (35), 18 - 33(36) , 25 - 29(37) ] .The system consisting of one supply point, 33 buses, 3 laterals, 37 branches, 5 loops or Tie switches (Switches no.33-37) normally open switches which are shown by dotted lines and 32 sectionalizing switches (Switches no. 1-32) normally closed switches which are indicated by solid lines. The total number of switchable lines for each of these loops is 6,4,6,5 and 5. The total real and reactive power for the whole system loads of the initial configuration are 3.715MW and 2.300MVAR, respectively. The base real power loss is $202.67 \mathrm{KW}$.

\section{B. Assumptions and constraints:}

(1). Power flow calculation is performed using $S_{\text {base }}=100 \mathrm{MVA}$ and $V_{\text {base }}=12.66 \mathrm{KV}$.

(2). Three small distributed generators that operated at unity power factors i.e. inject

(3). only pure real power are installed in to the system in case $-3 \& 4$..

(4). The bus at which load is connected is considered as the location for DG.

(5). The source bus is not considered as the location for DG placement.

(6). The limits of DG unit sizes for installation at system bus locations are assumed to be

(7). 0 to $2 \mathrm{MW}$.

(8). Voltage at the primary bus of a substation is 1.0 p.u.

(9). The upper and lower limits of voltage for each bus are 1.05p.u. and 0.9 p.u.,

(10). respectively.

(11). The maximum allowable number of the parallel DG is one, in each bus. 
(12). The load model which is used in the simulations is uniform with constant power.

\section{Simulation Results and Discussion:}

The proposed method has been implemented by using Mat-lab programs and run on a personal computer with Pentium dual core processor having 1.86GHZ speed and 1GB RAM. To validate the effectiveness of the proposed algorithm, the HC - ACO algorithm has been implemented to 33-bus radial distribution system and simulation results are compared with other techniques as reported in the literature for real power loss objective function having four cases.

Case-1: The system is without distributed generators and feeder reconfiguration (Base case).

Case-2: The same as case-1 except that the feeder can be reconfigured by the available sectionalizing switches and the tie switches.

Case-3: The same as case-1 except that there are 3 numbers of DG units installed who can provide only firm active power to the system.

Case-4: Reconfiguration and installing DG units simultaneously in the base configuration.

In this paper the main parameters used in HC-ACO are $N=10, \alpha=0.1, \beta=0.9$, $\rho=0.04, \tau_{0}=1, H_{\max }=100$, and $W_{\max }=10$. To find the minimum fitness (objective function value), the $\mathrm{HC}-\mathrm{ACO}$ is run for 10 independent runs.

The magnitude of bus voltage at each bus for different cases is shown in Table I. The bus voltage deviation, minimum bus voltage with bus number, bus voltage improvement and increment in minimum bus voltage are given in Table III \& IV. The voltage profile of the system for different cases are shown in Figure 4, 5, 6 and 7. The minimum bus voltage (MBV) of the initial configuration of the system for case- 1 is that of bus 18 and is equal to 0.9052 p.u. In case-2, most of the bus voltage are improved after reconfiguration as shown in Figure 5 such that the MBV value is that of bus 32 equals to 0.9385 p.u. achieving $2.781 \%$ improvement than case-1(base case). In case-3, adding three number DG units with optimal placement and sizing to the base configuration of the system, all bus voltages are improved as shown in Figure 6 and the MBV value is improved to 0.9504p.u. achieving $4.084 \%$ improvement than case-1(base case). After reconfiguration adding three number DG units with optimal placement and sizing (case-4), most of the bus voltages are improved and the MBV value is improved by $4.654 \%$ with respect to case-1(base case) as shown in Figure 7.

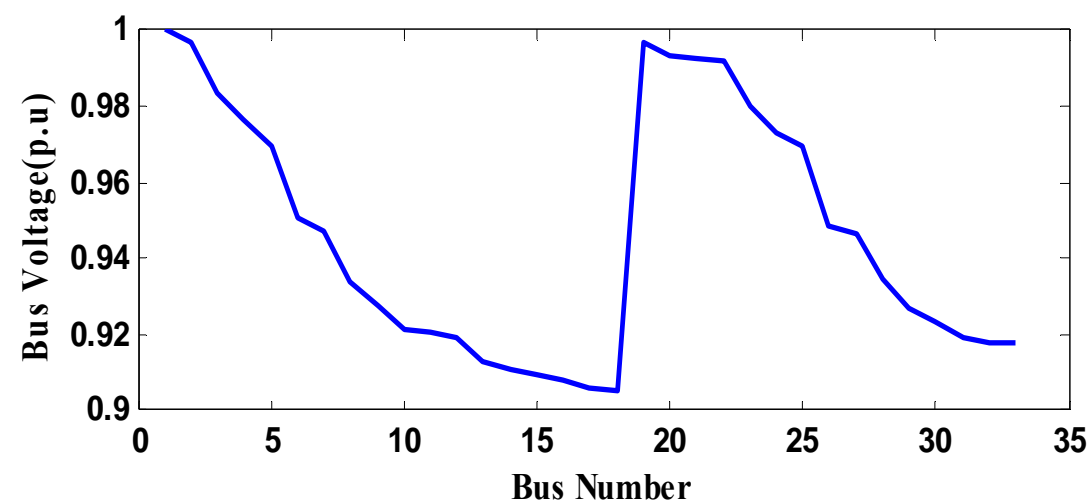

Figure 4. Voltage profiles at various buses for case-1. 


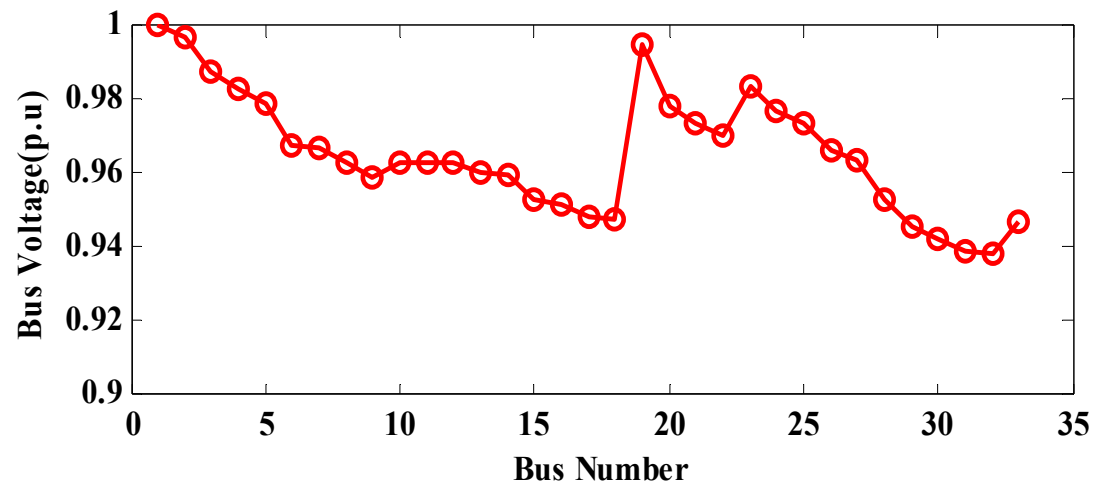

Figure 5. Voltage profiles at various buses for case-2.

Table 1.

Bus voltage magnitudes of 33- Bus System

\begin{tabular}{|c|c|c|c|c|c|}
\hline \multirow{2}{*}{ Bus No. } & \multirow{2}{*}{ Case -1 } & \multicolumn{2}{|c|}{ Case -2 } & \multirow{2}{*}{ Case -3} & \multirow{2}{*}{ Case-4 } \\
\hline & & HSA $[8]$ & HC-ACO & & \\
\hline 1 & 1.0000 & 1.000 & 1.0000 & 1.0000 & 1.0000 \\
\hline 2 & 0.9971 & 0.9971 & 0.9971 & 0.9974 & 0.9974 \\
\hline 3 & 0.9835 & 0.9869 & 0.9874 & 0.9882 & 0.9886 \\
\hline 4 & 0.9763 & 0.9823 & 0.9831 & 0.9843 & 0.9851 \\
\hline 5 & 0.9693 & 0.9778 & 0.9788 & 0.9806 & 0.9817 \\
\hline 6 & 0.9508 & 0.9666 & 0.9679 & 0.9715 & 0.9734 \\
\hline 7 & 0.9473 & 0.9659 & 0.9673 & 0.9709 & 0.9728 \\
\hline 8 & 0.9337 & 0.9653 & 0.9627 & 0.9716 & 0.9693 \\
\hline 9 & 0.9274 & 0.9621 & 0.9593 & 0.9698 & 0.9674 \\
\hline 10 & 0.9215 & 0.9616 & 0.9628 & 0.9688 & 0.9663 \\
\hline 11 & 0.9206 & 0.9681 & 0.9628 & 0.9688 & 0.9664 \\
\hline 12 & 0.9191 & 0.9683 & 0.9631 & 0.9718 & 0.9667 \\
\hline 13 & 0.9130 & 0.9657 & 0.9606 & 0.9692 & 0.9642 \\
\hline 14 & 0.9107 & 0.9649 & 0.9598 & 0.9684 & 0.9634 \\
\hline 15 & 0.9093 & 0.9574 & 0.9533 & 0.9689 & 0.9644 \\
\hline 16 & 0.9079 & 0.9561 & 0.9515 & 0.9516 & 0.9637 \\
\hline 17 & 0.9058 & 0.9541 & 0.9486 & 0.9524 & 0.9630 \\
\hline 18 & 0.9052 & 0.9536 & 0.9476 & 0.9520 & 0.9556 \\
\hline 19 & 0.9966 & 0.9953 & 0.9951 & 0.9959 & 0.9957 \\
\hline 20 & 0.9930 & 0.9802 & 0.9783 & 0.9829 & 0.9812 \\
\hline 21 & 0.9923 & 0.9760 & 0.9737 & 0.9794 & 0.9772 \\
\hline 22 & 0.9917 & 0.9733 & 0.9702 & 0.9768 & 0.9738 \\
\hline 23 & 0.9799 & 0.9833 & 0.9838 & 0.9846 & 0.9851 \\
\hline 24 & 0.9732 & 0.9767 & 0.9772 & 0.9780 & 0.9784 \\
\hline 25 & 0.9699 & 0.9734 & 0.9739 & 0.9747 & 0.9751 \\
\hline 26 & 0.9489 & 0.9647 & 0.9662 & 0.9701 & 0.9722 \\
\hline 27 & 0.9464 & 0.9622 & 0.9638 & 0.9682 & 0.9705 \\
\hline 28 & 0.9349 & 0.9510 & 0.9533 & 0.9599 & 0.9633 \\
\hline 29 & 0.9267 & 0.9429 & 0.9458 & 0.9541 & 0.9583 \\
\hline 30 & 0.9232 & 0.9395 & 0.9426 & 0.9517 & 0.9563 \\
\hline 31 & 0.9190 & 0.9354 & 0.9391 & 0.9504 & 0.9560 \\
\hline 32 & 0.9181 & 0.9345 & 0.9385 & 0.9504 & 0.9559 \\
\hline 33 & 0.9178 & 0.9342 & 0.9472 & 0.9514 & 0.9560 \\
\hline
\end{tabular}


Table 2.

Bus Voltage Angles of 33- Bus System

\begin{tabular}{|c|c|c|c|c|c|}
\hline \multirow{2}{*}{ Bus No. } & \multirow{2}{*}{ Case -1} & \multicolumn{2}{|c|}{ Case -2 } & \multirow{2}{*}{ Case -3} & \multirow{2}{*}{ Case-4 } \\
\hline & & HSA $[8]$ & HC-ACO & & \\
\hline 1 & 1.0000 & 1.000 & 1.0000 & 1.0000 & 1.0000 \\
\hline 2 & 0.9971 & 0.9971 & 0.9971 & 0.9974 & 0.9974 \\
\hline 3 & 0.9835 & 0.9869 & 0.9874 & 0.9882 & 0.9886 \\
\hline 4 & 0.9763 & 0.9823 & 0.9831 & 0.9843 & 0.9851 \\
\hline 5 & 0.9693 & 0.9778 & 0.9788 & 0.9806 & 0.9817 \\
\hline 6 & 0.9508 & 0.9666 & 0.9679 & 0.9715 & 0.9734 \\
\hline 7 & 0.9473 & 0.9659 & 0.9673 & 0.9709 & 0.9728 \\
\hline 8 & 0.9337 & 0.9653 & 0.9627 & 0.9716 & 0.9693 \\
\hline 9 & 0.9274 & 0.9621 & 0.9593 & 0.9698 & 0.9674 \\
\hline 10 & 0.9215 & 0.9616 & 0.9628 & 0.9688 & 0.9663 \\
\hline 11 & 0.9206 & 0.9681 & 0.9628 & 0.9688 & 0.9664 \\
\hline 12 & 0.9191 & 0.9683 & 0.9631 & 0.9718 & 0.9667 \\
\hline 13 & 0.9130 & 0.9657 & 0.9606 & 0.9692 & 0.9642 \\
\hline 14 & 0.9107 & 0.9649 & 0.9598 & 0.9684 & 0.9634 \\
\hline 15 & 0.9093 & 0.9574 & 0.9533 & 0.9689 & 0.9644 \\
\hline 16 & 0.9079 & 0.9561 & 0.9515 & 0.9516 & 0.9637 \\
\hline 17 & 0.9058 & 0.9541 & 0.9486 & 0.9524 & 0.9630 \\
\hline 18 & 0.9052 & 0.9536 & 0.9476 & 0.9520 & 0.9556 \\
\hline 19 & 0.9966 & 0.9953 & 0.9951 & 0.9959 & 0.9957 \\
\hline 20 & 0.9930 & 0.9802 & 0.9783 & 0.9829 & 0.9812 \\
\hline 21 & 0.9923 & 0.9760 & 0.9737 & 0.9794 & 0.9772 \\
\hline 22 & 0.9917 & 0.9733 & 0.9702 & 0.9768 & 0.9738 \\
\hline 23 & 0.9799 & 0.9833 & 0.9838 & 0.9846 & 0.9851 \\
\hline 24 & 0.9732 & 0.9767 & 0.9772 & 0.9780 & 0.9784 \\
\hline 25 & 0.9699 & 0.9734 & 0.9739 & 0.9747 & 0.9751 \\
\hline 26 & 0.9489 & 0.9647 & 0.9662 & 0.9701 & 0.9722 \\
\hline 27 & 0.9464 & 0.9622 & 0.9638 & 0.9682 & 0.9705 \\
\hline 28 & 0.9349 & 0.9510 & 0.9533 & 0.9599 & 0.9633 \\
\hline 29 & 0.9267 & 0.9429 & 0.9458 & 0.9541 & 0.9583 \\
\hline 30 & 0.9232 & 0.9395 & 0.9426 & 0.9517 & 0.9563 \\
\hline 31 & 0.9190 & 0.9354 & 0.9391 & 0.9504 & 0.9560 \\
\hline 32 & 0.9181 & 0.9345 & 0.9385 & 0.9504 & 0.9559 \\
\hline 33 & 0.9178 & 0.9342 & 0.9472 & 0.9514 & 0.9560 \\
\hline
\end{tabular}




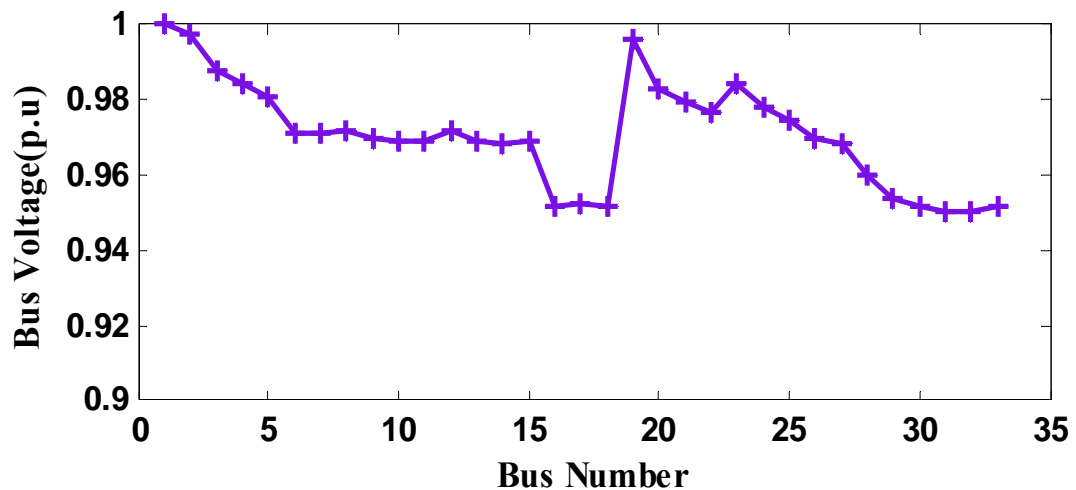

Figure 6. Voltage profiles at various buses for case-3.



Figure 7. Voltage profiles at various buses for case-4.

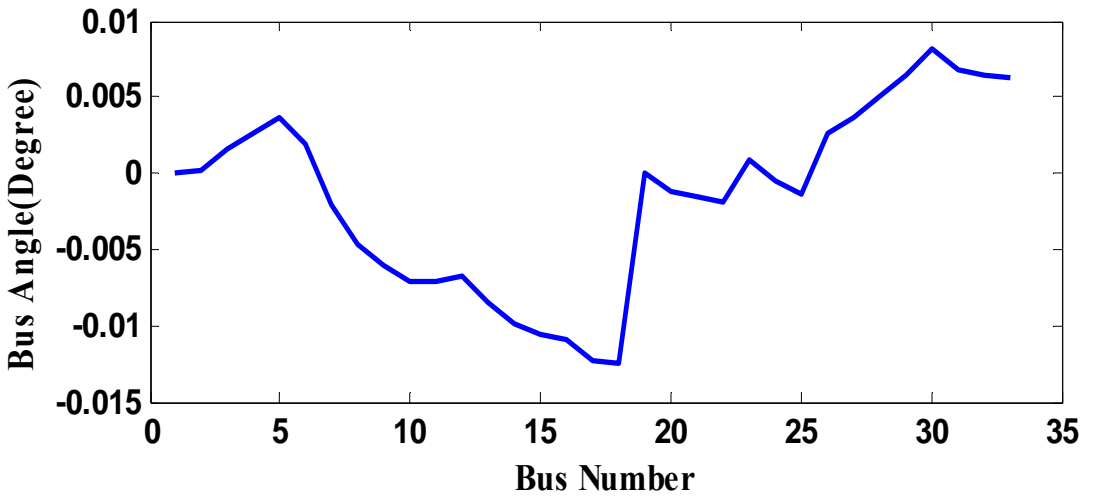

Figure 8. Voltage angles at various buses for case-1. 


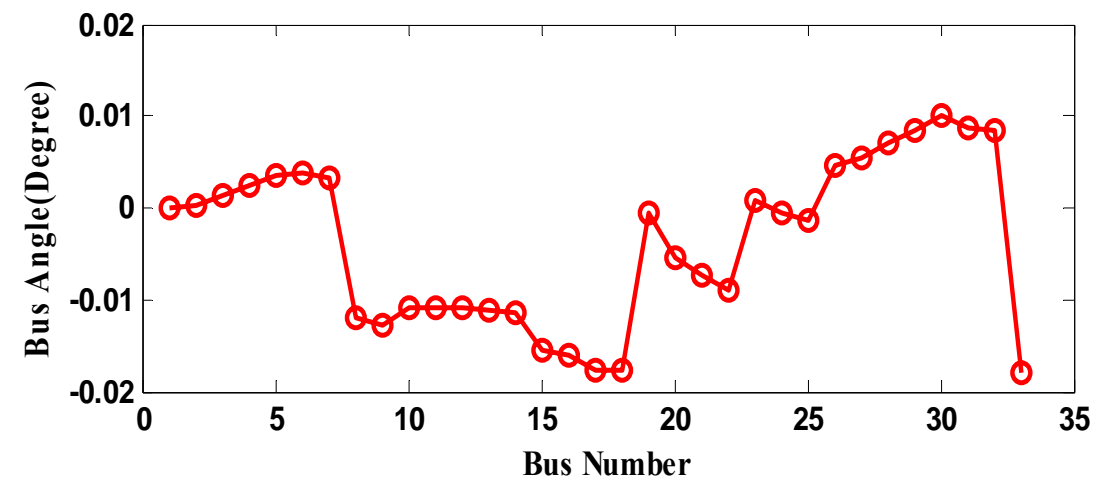

Figure 9. Voltage angles at various buses for case-2.

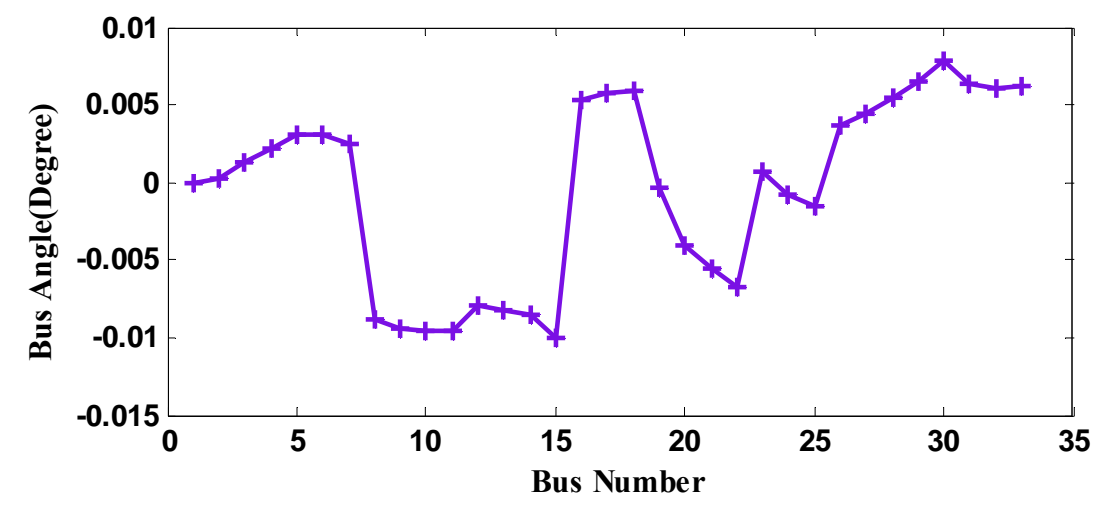

Figure 10. Voltage angles at various buses for case-3.

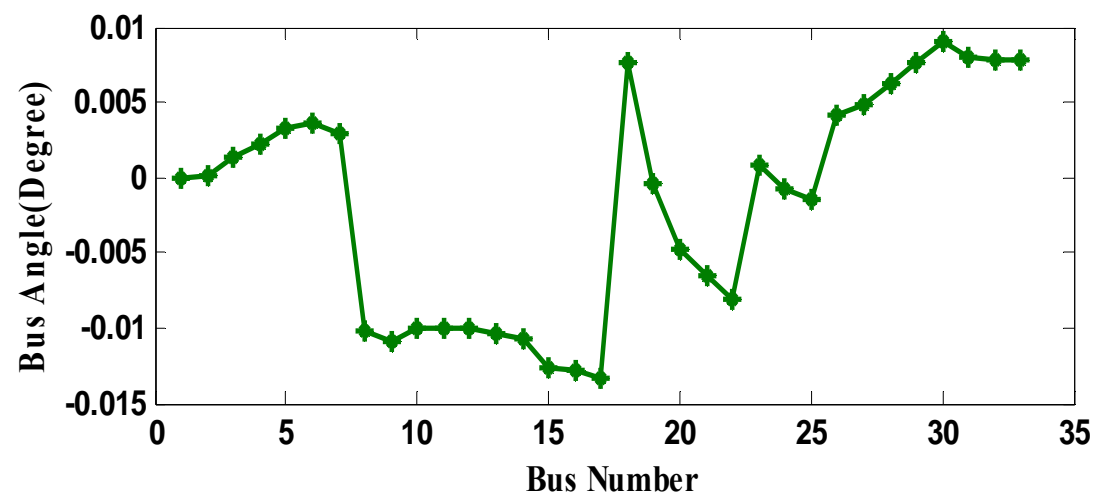

Figure 11. Voltage angles at various buses for case-4. 
Table 3.

Comparison of Results using HC- ACO

\begin{tabular}{|l|c|c|c|c|}
\hline \multicolumn{1}{|c|}{ Item } & Case- 1 & Case -2 & Case- 3 & Case-4 \\
\hline Real power loss (KW) & 202.67 & 136.30 & 96.34 & 93.45 \\
\hline Bus voltage deviation & 0.3111 & 0.1981 & 0.1681 & 0.1628 \\
\hline $\mathbf{V}_{\text {min }}$ (p .u.) / Bus No. & $0.9052 / 18$ & $0.938 / 32$ & $0.9504 / 31$ \& 32 & $0.9556 / 18$ \\
\hline Tie switches & $33,34,35,36,37$ & $7,14,9,32,37$ & $33,34,35,36,37$ & $7,14,9,17,37$ \\
\hline Location of DG & - & - & $18,17,32$ & $33,32,31$ \\
\hline Size of DG (MW) & - & - & 0.1082, & 0.2572, \\
& & & 0.5800, & 0.1782, \\
& & & 1.0520 & 0.6640 \\
\hline
\end{tabular}

Table 4.

Comparison of Results in \% with respect to Case - 1 using HC- ACO

\begin{tabular}{|l|c|c|c|}
\hline \multicolumn{1}{|c|}{ Item } & Case -2 & Case -3 & Case -4 \\
\hline Real power loss reduction (\%) & 32.74 & 52.46 & 53.89 \\
\hline Bus voltage improvement (\%) & 36.3227 & 45.9659 & 47.6695 \\
\hline Increment in minimum bus voltage (\%) ) & 2.781 & 4.084 & 4.654 \\
\hline No. of tie switches changed & 4 & 0 & 4 \\
\hline
\end{tabular}

The value of bus voltage angles at each bus for different cases is shown in Table II. The angle of the voltages at various buses in the system for different cases is shown in Figure 8, 9, 10 and 11. The improvement in angles of voltages in the system for different cases ( Figure 9, 10 and 11) is an indication of relieving of overload on feeders of the system. From Figure8, 9, 10 and 11, It is observed that the feeders in middle of the system are relived of high load than those at ends.

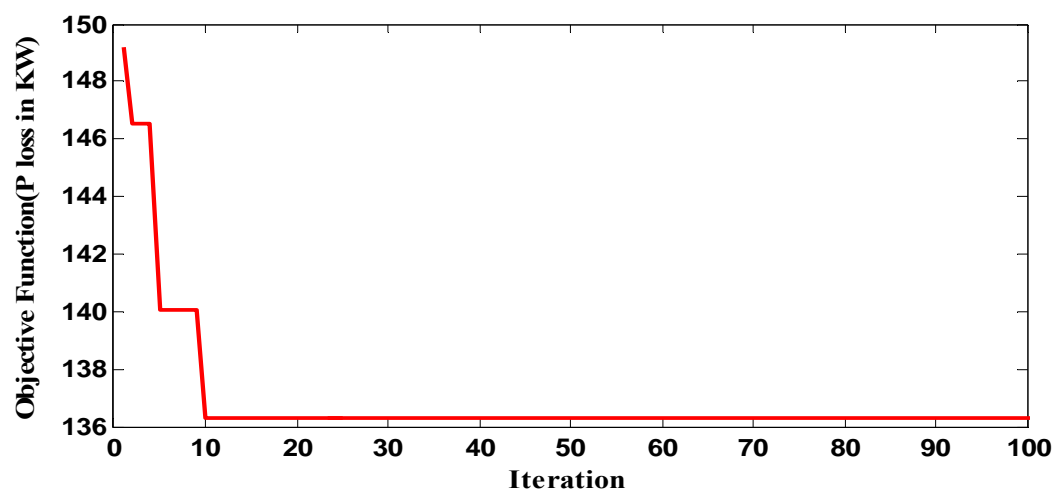

Figure 12. Convergence characteristics for case-2 


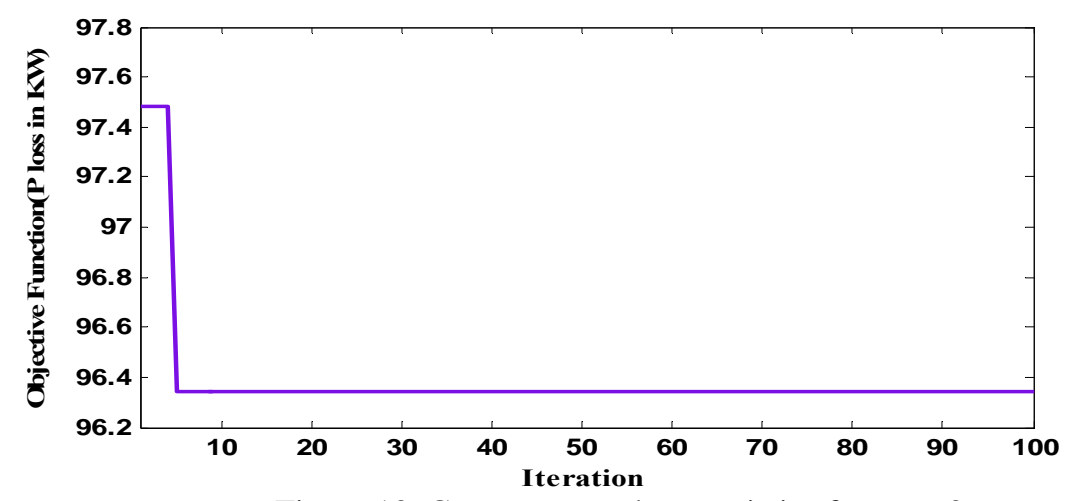

Figure 13. Convergence characteristics for case-3

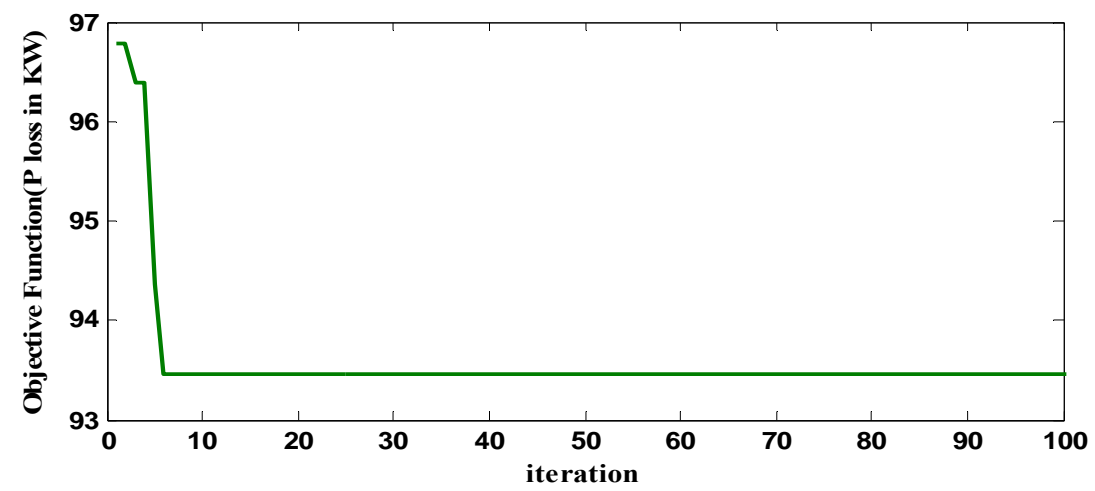

Figure 14. Convergence characteristics for case-4

The results obtained through different cases taking power loss into account as objective function are shown in Table 3 and 4 . As shown, reconfiguration of the system before the DG units are added (case-2) resulted in the final configuration [7, 14, 9, 32, 37] with total power loss of $136.30 \mathrm{KW}$. This amount to $32.74 \%$ reduction in losses than case-1. In case-3, inclusion of DG units in the base configuration of the system reduced the total power losses of case- 1 by $52.46 \%$. Reconfiguration of the network with the existence of DG units as in case-4 reduced power losses by $53.89 \%$ with respect to base case (case-1) .In Figure 12, 13 and 14, the convergence characteristics of the aforementioned evolutionary algorithm for cases-2, 3 and 4 are depicted.

From Table 3 and 4, it is observed that improvement in power loss reduction and voltage profile for case- 4 are higher when compared to other cases (1, 2 and 3). This indicates that DG installation after reconfigurations gives better results.

Candidate bus location by using sensitivity analysis and size of three numbers of DG units for case 3 and 4 are given in table 3 . 
Now, the proposed HC-ACO is compared with other methods such as HSA [8], GA [8] , RGA [8] . The results are shown in Table V. As can be seen from this table proposed method gives better results compared to other.

Table 5.

Comparison of Simulation Results of 33-Bus System

\begin{tabular}{|c|c|c|c|c|}
\hline Method & Item & Case-2 & Case-3 & Case -4 \\
\hline \multirow{6}{*}{$\begin{array}{l}\text { HC- } \\
\text { ACO }\end{array}$} & DG placement & -------- & $18.17 \quad 32$ & 33,3231 \\
\hline & DG Size & -------- & 1.7402 & 1.0994 \\
\hline & Open Switches & $7,14,9,32,37$ & $33,34,35,36,37$ & $7,14,9,17,37$ \\
\hline & Real Power loss(KW) & 136.30 & 96.34 & 93.45 \\
\hline & $\%$ Real Power loss & 32.74 & 52.46 & 53.89 \\
\hline & $\mathrm{V}_{\min }$ (p.u.) & 0.9342 & 0.9385 & 0.9504 \\
\hline \multirow{6}{*}{ HSA [8] } & DG placement & ---------- & $18,17,33$ & $32,31,30$ \\
\hline & DG Size & ---------- & 1.7256 & 1.0909 \\
\hline & Open Switches & $7,14,9,32,37$ & $33,34,35,36,37$ & $7,14,9,32,37$ \\
\hline & Real Power loss (KW) & 138.06 & 96.76 & 97.13 \\
\hline & $\% \quad$ Real Power loss & 31.88 & 52.26 & 52.07 \\
\hline & $\mathrm{V}_{\min }$ (p.u.) & 0.9310 & 0.9670 & 0.9479 \\
\hline \multirow{6}{*}{ GA $[8]$} & DG placement & -------- & -------- & -------- \\
\hline & DG Size & -------- & 1.6044 & 1.448 \\
\hline & Open Switches & $33,9,34,28,36$ & $33,34,35,36,37$ & $33,9,34,28,36$ \\
\hline & Real Power loss(KW) & 141.60 & 100.1 & 98.36 \\
\hline & $\% \quad$ Real Power loss & 30.15 & 50.60 & 51.46 \\
\hline & $\mathrm{V}_{\min }$ (p.u.) & 0.9310 & 0.9605 & 0.9506 \\
\hline \multirow{6}{*}{ RGA[8] } & DG placement & -------- & -------- & -------- \\
\hline & DG Size & ------- & 1.777 & 1.100 \\
\hline & Open Switches & $7,14,9,2,37$ & $33,34,35,36,37$ & $7,14,9,32,37$ \\
\hline & Real Power loss (KW) & 139.46 & 97.60 & 98.23 \\
\hline & $\%$ Real Power loss & 31.20 & 51.84 & 51.53 \\
\hline & $\mathrm{V}_{\min }($ p.u. $)$ & 0.93515 & 0.9687 & 0.9479 \\
\hline
\end{tabular}

\section{Conclusion}

In this paper, the HC-ACO algorithm is proposed to reduce distribution system losses. The validity of the results and effectiveness of $\mathrm{HC}-\mathrm{ACO}$ is investigated by a 33 buses, $12.66 \mathrm{KV}$ radial distribution system. The merits of the HC-ACO is that it reached the optimum solution in a fewer iterations than the HSA since the HC-ACO is a constructive and greedy search approach that make use of positive feedback such as the gradient information of the objective function as well as pheromone trails and heuristic information that guide the search and lead to rapid discovery of good solutions. That is why requires less practice to reach the optimum solution while HSA is a random search that does not require any prior information to generate a solution vector and so needs a lot of practice to identify the solution space and to reach the optimum solution in a reasonable time. The Convergence characteristics of general ACO algorithm , the optimum solution is reached at higher iteration compared to only a fewer iterations for the $\mathrm{HC}-\mathrm{ACO}$ algorithm .It is clear that implementing ACO algorithm in the Hyper-Cube (HC) framework comes with the benefit of scaling objective function value allowing rapid discovery of good solutions and fast optimum convergence. The computational results of the 33-bus system show that the HC-ACO method is better than the HSA one. From the results of this paper, it can be seen that DG has the improvement effects on loss reduction 
and can decrease the system bus voltage deviation. It can be observed that more loss reduction can be achieved by the HC-ACO comparing with the other methods when reconfiguration of the feeder is done with installing DG units. Test results show that the proposed algorithm is very fast and gives optimal solution.

\section{References}

[1] Baran, M .E. and Wu, F.F. "Network reconfiguration in distribution systems for loss reduction and load balancing”, IEEE Trans. Power Deliv., Vol. 4, No. 2, pp. 14011407,1989 .

[2] A.Merlin and H. Back. "Search for a minimal-loss operating spanning tree configuration in an urban Power distribution system," in Proc. $5^{\text {th }}$ Power System Computation Conf. (PSCC), Cambridge, U.K.pp.118, 1975.

[3] D. Shirmohammadi and H. W. Hong, "Reconfiguration of electric distribution networks for resistive line losses reduction”, IEEE Trans. Power Del., vol. 4, no. 2, pp. 1492$1498,1989$.

[4] S. Civanlar, J. Grainger, H. Yin, and S. Lee, "Distribution feeder reconfiguration for loss reduction”, IEEE Trans. Power Del., vol. 3, no.3, pp. 1217-1223, 1988.

[5] D. Das, "A fuzzy multi-objective approach for network reconfiguration of distribution systems”, IEEE Trans. Power Del., vol. 21, no. 1, pp. 202-209, 2006.

[6] K. Nara, A. Shiose, M. Kitagawoa, and T. Ishihara, "Implementation of genetic algorithm for distribution systems loss minimum reconfiguration”, IEEE Trans. Power Syst., vol. 7, no. 3, pp. 1044-1051, Aug.1992.

[7] J. Z. Zhu, "Optimal reconfiguration of electrical distribution network using the refined genetic algorithm”, Elect. Power Syst. Res., vol. 62, pp. 37-42, 2002.

[8] R. Srinivasa Rao, K.Ravindra K.Satish and S. V. L. Narasimham, "Power Loss Minimization in Distribution System Using Network Reconfiguration in the presence of Distributed Generation”, IEEE Trans. Power Syst., vol. 28, no. 1, pp. 317-325,2013.

[9] C. Wang and M. H. Nehrir "Analytical approaches for optimal placement of distributed generation sources in power systems”, IEEE Trans. Power Syst., vol. 19, no. 4, pp. 20682076,2004.

[10] W. Rosehart and E. Nowicki, "Optimal placement of distributed generation", in Proc. 14th Power Systems Computation Conf., Sevillla, pp. 1-5, Section 11, paper 2, 2002.

[11] G. Celli, E. Ghiani, S. Mocci, and F. Pilo, "A multi-objective evolutionary algorithm for the sizing and the sitting of distributed generation”, IEEE Trans. Power Syst., vol. 20, no. 2, pp. 750-757, 2005.

[12] P. Agalgaonkar, S. V. Kulkarni, S. A. Khaparde, and S. A. Soman, "Placement and penetration of distributed generation under standard market design", Int.J. Emerg. Elect. Power Syst., vol.1, no.1,2004

[13] Haque, M.H.. 'Efficient load flow method for distribution systems with radial or mesh configuration'. IEE Proc. On Generation, Transmission and Distribution. 1996, 143 (1): 33-38.

[14] Kumar, I.S., Kumar, N.P. 'A novel approach to identify optimal access point and capacity of multiple DGs in a small, medium and large scale radial distribution systems', Int. J. Elect. Power Energy Syst., 2013, 45, (1), pp. 142-151.

[15] C. Blum, "Ant colony optimization: introduction and recent trends", Physics of Life Review 2, ELSERVIER, pp. 354-373, 2005.

[16] M. Dorigo and T.Stulzle, "The ant colony optimization metaheuristics: algorithms, applications and advances”, In Handbook of Metaheuristics, F.Glover and G. Kochenberger ,EDS, Norwell, MA: Kluwer , ,International Series in Operation Research and Management Science, Vol.57,pp.251-285,2000.

[17] S. Alonso, O. Cordon, F.de Viana and F.Herrera, "Integrating Evolutionary computation components in Ant colony optimization” Recent Developments in Biologically Inspired Computing, Ideal Group Publishing, pp.148-180, 2004. 
[18] E. Carpaneto and G. Chicco, "Distribution system minimum loss reconfiguration in the Hyper-Cube Ant Colony Optimization framework", Electric Power Systems Research, vol.78, pp. 2037-2045, 2008.

[19] C. Blum and M. Dorigo, "The hyper cube framework for ant colony optimization", IEEE Trans. System Man and Cybernatics, vol.34, pp. 1161-1172, 2004.

\section{Appendix}

Table A. I

Data for 33-bus test system

\begin{tabular}{|c|c|c|c|c|c|c|}
\hline \multirow{2}{*}{$\begin{array}{c}\text { Line } \\
\text { No. }\end{array}$} & \multirow[b]{2}{*}{$\begin{array}{c}\text { From } \\
\text { Bus }\end{array}$} & \multirow[b]{2}{*}{$\begin{array}{c}\text { To } \\
\text { Bus }\end{array}$} & \multirow[b]{2}{*}{$\mathbf{R}(\Omega)$} & \multirow[b]{2}{*}{$\mathrm{X}(\boldsymbol{\Omega})$} & \multicolumn{2}{|c|}{ Receiving End Bus } \\
\hline & & & & & $P_{\text {Load }}(K W)$ & $\begin{array}{c}\mathbf{Q}_{\text {Load }} \\
\text { (KVAR) }\end{array}$ \\
\hline 1 & Main SS & 2 & 0.0922 & 0.0477 & 100.0 & 100.0 \\
\hline 2 & 2 & 3 & 0.4930 & 0.2511 & 90.0 & 90.0 \\
\hline 3 & 3 & 4 & 0.3660 & 0.1864 & 120.0 & 80.0 \\
\hline 4 & 4 & 5 & 0.3811 & 0.1941 & 60.0 & 30.0 \\
\hline 5 & 5 & 6 & 0.8190 & 0.7070 & 60.0 & 20.0 \\
\hline 6 & 6 & 7 & 0.1872 & 0.6188 & 200.0 & 100.0 \\
\hline 7 & 7 & 8 & 1.7114 & 1.2351 & 1.2351 & 100.0 \\
\hline 8 & 8 & 9 & 1.0300 & 0.7400 & 0.7400 & 20.0 \\
\hline 9 & 9 & 10 & 1.0400 & 0.7400 & 60.0 & 20.0 \\
\hline 10 & 10 & 11 & 0.1966 & 0.0650 & 45.0 & 30.0 \\
\hline 11 & 11 & 12 & 0.3744 & 0.1238 & 60.0 & 35.0 \\
\hline 12 & 12 & 13 & 1.4680 & 1.1550 & 60.0 & 35.0 \\
\hline 13 & 13 & 14 & 0.5416 & 0.7129 & 120.0 & 80.0 \\
\hline 14 & 14 & 15 & 0.5910 & 0.5260 & 60.0 & 10.0 \\
\hline 15 & 15 & 16 & 0.7463 & 0.5450 & 60.0 & 20.0 \\
\hline 16 & 16 & 17 & 1.2890 & 1.7210 & 60.0 & 20.0 \\
\hline 17 & 17 & 18 & 0.7320 & 0.5740 & 90.0 & 40.0 \\
\hline 18 & 2 & 19 & 0.1640 & 0.1565 & 90.0 & 40.0 \\
\hline 19 & 19 & 20 & 1.5042 & 1.3554 & 90.0 & 40.0 \\
\hline 20 & 20 & 21 & 0.4095 & 0.4784 & 90.0 & 40.0 \\
\hline 21 & 21 & 22 & 0.7089 & 0.9373 & 90.0 & 40.0 \\
\hline 22 & 3 & 23 & 0.4512 & 0.3083 & 90.0 & 50.0 \\
\hline 23 & 23 & 24 & 0.8980 & 0.7091 & 420.0 & 200.0 \\
\hline 24 & 24 & 25 & 0.8960 & 0.7011 & 420.0 & 200.0 \\
\hline 25 & 6 & 26 & 0.2030 & 0.1034 & 60.0 & 25.0 \\
\hline 26 & 26 & 27 & 0.2842 & 0.1447 & 60.0 & 25.0 \\
\hline 27 & 27 & 28 & 1.0590 & 0.9337 & 60.0 & 20.0 \\
\hline 28 & 28 & 29 & 0.8042 & 0.7006 & 120.0 & 70.0 \\
\hline 29 & 29 & 30 & 0.5075 & 0.2585 & 200.0 & 600.0 \\
\hline 30 & 30 & 31 & 0.9744 & 0.9630 & 150.0 & 150.0 \\
\hline 31 & 31 & 32 & 0.3105 & 0.3619 & 210.0 & 210.0 \\
\hline 32 & 32 & 33 & 0.3410 & 0.5302 & 60.0 & 60.0 \\
\hline 33* & 21 & 8 & 0.0000 & 2.0000 & & \\
\hline $34 *$ & 9 & 15 & 0.0000 & 2.0000 & & \\
\hline 35* & 12 & 22 & 0.0000 & 2.0000 & & \\
\hline $36^{*}$ & 18 & 33 & 0.0000 & 2.0000 & & \\
\hline $37 *$ & 25 & 29 & 0.0000 & 2.0000 & & \\
\hline
\end{tabular}


Table A.II

Loop details for 33-bus radial system

\begin{tabular}{|c|c|c|c|c|c|c|}
\hline Loop & \multicolumn{7}{|c|}{ Line Numbers } \\
\hline Loop-1 & 33 & 18 & 19 & 20 & 06 & 07 \\
\hline Loop-2 & 34 & 4 & 13 & 14 & & \\
\hline Loop-3 & 35 & 08 & 11 & 10 & 09 & 21 \\
\hline Loop-4 & 36 & 32 & 17 & 16 & 15 & \\
\hline Loop-5 & 37 & 24 & 23 & 22 & 28 & \\
\hline
\end{tabular}

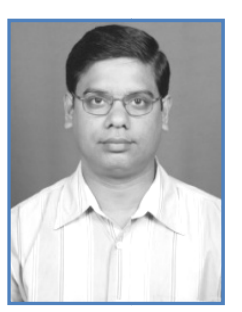

Manas Ranjan Nayak was born in 1972, india. He received his B.E. degree in Electrical Engineering from I.G.I.T.Sarang (Utkal University, India) and M.E. degree in Electrical Engineering from U.C.E., Burla (Sambalpur University, India) in 1994 and 1995 respectively. For 1998 - 2008, he was with Orissa Hydro Power Corporation Ltd. (A Govt. Orissa PSU) as Asst. Manager (Electrical) and since 2008 he has been with Electrical Engineering Deptt. , ITER, Siksha 'O’ Anusandhan University, Bhubaneswar, Odisha, India-751030 and continuing as an Associate Professor. His research interests include power system operation and planning, Distribution Network, Distributed Generation, FACTS and Application of Soft computing techniques to power system optimization. Prof. Nayak has membership in professional societies i.e. IET (70472641) and ISTE (LM-71207) 